\title{
Health Risky Behaviors Among University Students: Prevalence And Effect Of Health Education Program.
}

\author{
Eman E. Oraby *, Amira E. Abdelsalam (*), Safaa A. Ali ** \\ * Public health and Community Medicine, Faculty of Medicine, Zagazig University. \\ ** Psychiatric \& Mental Health Nursing, Faculty of Nursing, El Fayoum University \\ Received : December, 2015 accepted : March 2016
}

\begin{abstract}
Background: University students are at high risk of health-risky behaviors that could lead to serious physical complications, social dysfunction, and psychological disturbances which require different treatment approaches. Also they face social, emotional and educational challenges when entering the University. Well organized health education programs can change such behaviors by increasing knowledge and influencing attitude and behavior. Objectives: The main objective of this study is to rate the most frequent health risky behaviors among university students and to evaluate the effect of health education program on the level of changing the health risky behaviors among university students. .Methods: An interventional study was used; the study was conducted on a sample of 853 randomly selected students at Zagazig University, during the $2^{\text {nd }}$ term of the academic year $2014-2015$. A structured questionnaire to assess types and prevalence of health risky behaviors before and after intervention was used. Additionally anthropometric measurements were calculated. Results: unhealthy dieting behavior took the lowest satisfactory score (10\%), followed by unhealthy nutritional behavior (17\%) and smoking behavior (33.3\%). The implementation of the educational program was effective in improving unhealthy behavior especially dieting behavior. Conclusion: health risk behaviors are common among college students, and raising awareness by regular health education programs can dramatically change the profile of these behaviors.
\end{abstract}

Key Words: University colleges, health, risky behaviors, health education. Corresponding author: Safaa Abdelazem Osman Ali E mail : safaa_abdelazem@yahoo.com

\section{Introduction}

Health-risk behaviors can be defined as any activity undertaken by person with a frequency or intensity that increases risk of disease or injury ${ }^{(I)}$. It might cluster together into a risky lifestyle which influences cognitive performance, emotions, and the overall quality of life. Much of the morbidity and mortality is caused by individual behavioral patterns, psychological affairs, polluted environment or poverty (2). Very few studies look at multiple behaviors for that smoking tends to be an elevated risk for other risk behaviors ${ }^{(3)}$. In a study performed by ${ }^{(4)}$ they noted that large number of university students smoke tobacco, binge drink, do not exercise enough and don't eat enough fruits and vegetables.

There are five categories of behaviors have been consistently found to correlate with increased morbidity and mortality identified by (5). They are consuming a diet high in calories, fat and sodium, and low in nutrients; low levels of physical activity and high levels of sedentary activity; smoking cigarettes; abusing substances including alcohol, remedy and illicit drugs, and engaging in risky sexual behaviors. Conversely, health protective behaviors are actions that reduce disease 
susceptibility or facilitate restoration of all aspects of health. Three health protective behaviors are established to be linked with better health and recovery from illness that are being physically active, eating fruits and vegetables, and being adherent with prescribed medication ${ }^{(6)}$.

Recent advances in brain research have confirmed a dangerous link between adolescence and health risk behaviors, clarifying the fact that adolescence is the critical period of risk for both health risk behaviors and its consequences. Adolescents are more vulnerable to health risk behavior than adults because the parts of the brain responsible for judgment, decision making, emotion and impulse control are not yet fully developed. Therefore, teens are more likely than adults to take risks, including experimenting with drug abuse and engaging in dangerous behaviors ${ }^{(7)}$.

The odds of having multiple risk behaviors increase over the course of development, especially during the teenage years. Through experimentation with substances, physical risks and sexual risk, some adolescents acquire unhealthy behaviors and peers that persist and discourage the development of other self-regulatory skills. Despite health promotion efforts, young adults continue to engage in high rates of health-risk behaviors as clarified by ${ }^{(8)}$.It is important to understand health-risk behaviors among youths, as modifications in this can enhance all dimensions of health, and lessen the risk of chronic illness later in life ${ }^{(9)}$.

Whether in the clinic, home, school, or community health setting, the psychiatric nurse plays an important role to provide education to college students. They have many opportunities to organize individual, group, or family counseling sessions. Because the values, acceptance, and recognition of peers are so important during adolescence, the group can provide the support for dealing with problems and effecting change in addition. Accordingly, the mental health nurse is in excellent position to increase adolescents' self-esteem, which encourages them to face their problem, and try to cope with rather than avoid them. Therefore, it is crucial for nurses to be culturally competent in order to care for adolescents ${ }^{(10)}$.

The role of the psychiatric nurse in a community health risk behaviors prevention program is an increasing awareness of the need for prevention of health risk behaviors related problems. The psychiatric nurse is especially equipped to strengthen the bonds among adolescents and parents, health agencies, school and university, law enforcement and hospitals to assist the community in the design and implementation of its own prevention program. The nurse provides the knowledge and assists the community in its health enhancement by using nursing theory, interpersonal process, research competencies, and teaching skills ${ }^{(11)}$.

\section{Rationale of the study:}

In Egypt, adolescents constitute approximately $33.5 \%$ from total population. Adolescents compose an important population group because their physical and emotional health is vital to the future of societies and because they require guidance and direction. The adolescence stage is considered a critical age and one of the most difficult and the most dangerous stages in human life as well as high prevalence of health risk behavior occur at this age group. This study attempts to throw out some light on 
importance of targeted health education programs at universities because the university stage is considered one of the vital stages in studying health risk behavior among adolescents would help them to resort to adaptive rather than maladaptive behaviors.

\section{Goal:}

Improving quality of life among university students by decreasing the prevalence of the most common health problems.

\section{Objectives:}

- To rate the most frequent health risk behaviors among university students.

- To evaluate the effect of health education program on the level of changing the health risk behaviours among university students.

\section{Subjects and Methods}

Study design, setting \& time: An interventional study (community trial) was conducted on Zagazig University students. The field work was carried out during the $2^{\text {nd }}$ term of the academic year $2014-2015$.

Sample size: was calculated using Epi info version $6.04^{(12)}$; According to the statistical letter of Zagazig University, the total number of registered students at the year 2013-2014 was 11987 student, with expected frequency of smoking as one of risky health behavior was $5.8 \%^{(13)}$, at confidence interval $95 \%$, with study power was $80 \%$. Accordingly, the total calculated sample size was 853 students.

Sampling technique: cluster sample technique was used in which the colleges of Zagazig University were listed, they are (15) faculties. Three colleges were chosen by simple random sample (two practical, faculty of medicine and faculty of science) and one theoretical (faculty of commerce). The college's students were divided into sampling unit (sections for the practical colleges and specialties for the theoretical one) one section or specialty was chosen from each grade of each college by simple random sample. A list with the names of the students in the chosen sections and specialties were obtained from the students affairs of each faculty. All students in the chosen section or specialty were the target population. The students were reached mostly at the class rooms so almost the same students were reached for health education program.

\section{Inclusion criteria for study sample:}

Egyptian, under graduate students in Zagazig University from both sexes.

\section{Ethical consideration:}

- An informed written consent was obtained from all students before participation; it included data about aim of the work, study design, site, time, subject and tool. They were informed that all collected data will be confidential and used for scientific purposes only. They were informed also that no invasive or painful techniques will be carried upon them.

- An approval from The Research Ethics Committee in Zagazig faculty of medicine and in El Fayoum faculty of Nursing was obtained before conduction of this work.

\section{Tools of data collection:}

1) Interview questionnaire sheet: The questionnaire was adopted and modified according to $\boldsymbol{A b d} \boldsymbol{E} \boldsymbol{L}$-Rahim (14), it was revised by four academic professors to assess its content and construction validity and it includes data about the following topics: 
Part I: Personal and socio demographic data of the students such as gender, age, college, grade, residence, living with whom, student-parent relationship (loving parents, frequent struggling with parents and telling parents about their problems) relation with peers (having big number of friends, enjoy being with them and sharing them with problems and good events in life) and religious commitment (as believing in the religion's role in protecting against risky behaviors and following basic religion instructions as praying).

Part II: This part was intended to assess student's health risk behaviors before and after health education program. It included a series of open and closed questions covering 5 categories of risky behaviors which are nutritional behavior, dieting, smoking, intake of tea and other substances, safety behaviors (including following traffic rules, safe use of harmful instruments at homes as knives and electrical devices, violence and illegal sexual intercourse), and driving behavior.

Part III: Medical history about chronic illness and compliance to treatment before and after health education program.

Scoring: practice items reported to be correct were scored " 1 " and the items not correct were scored"0". For each health risky behavior, the scores of the items were summed-up then these scores were converted into a percent score. Practice was considered satisfactory if the percent score was $60 \%$ or more and unsatisfactory if less than $60 \%$ (this cutoff point was the median of the answers according to the results obtained from the pilot study).

2) Anthropometric measurements: The height in meters and the weight in kilograms of each studied students were measured, and then body mass index (BMI) was calculated. BMI was classified as normal (BMI=18.5-24.9 $\left.\mathrm{kg} / \mathrm{m}^{2}\right), \quad$ overweight $\quad(\mathrm{BMI}=25-29.9$ $\left.\mathrm{kg} / \mathrm{m}^{2}\right)$, and obese $\left(\mathrm{BMI} \geq 30 \mathrm{~kg} / \mathrm{m}^{2}\right)^{(15)}$.

Data collection procedures: The fieldwork of the current study was carried out through 5 phases

1- Pilot study: that was applied on $10 \%$ of the calculated sample. Its main goal was to assess the validity of the questionnaire and to assess acceptability of the students to the topic of the research. Some questions were not accepted at first as asking about sexual life, so the questions about this item were only limited to asking only about having illegal sexual intercourse. The results of pilot were not included on the final results of the research.

2- Assessment phase was intended for obtaining baseline data from students. This helped in the preparation of the educational program, and also as a pre test for further comparison before implementation of the health education program. The researchers first introduced themselves to students, and explained to them the purpose of the study briefly and an oral consent for participation was obtained.

3- Planning phase based on the results obtained from the assessment phase, the researchers designed the content of health education program. Accordingly, the program general and specific objectives were set, and the educational materials were prepared for each session. The researchers also prepared an illustrated booklet to help participants after the sessions. The contents of the booklet covered healthy nutritional behavior, dieting behavior, frequency of tea/coffee intake per day and 
hazard of smoking and substance abuse, safety behaviors, driving behavior and importance of compliance to treatment. The teaching methods included lectures and group discussions (to identify the health risk behaviours from the point of view of the students as many of them tolerated the harmful effect of some beahviors and considered it as normal especially as regards smoking). The teaching media used involved posters in addition to the program booklet prepared by the researchers. The health education message included an orientation to the program objectives; this was followed by covering important issues related to healthy nutritional behavior, dieting behavior, frequency of tea/coffee intake per day, hazard of smoking and substance abuse, safety behaviours (as following traffic rules, use of harmful instruments at home as electrical devices, violence, and having illegal sexual intercourse) driving behavior and importance of compliance to treatment.

4- Implementation phase: The health education program was implemented to the students in groups (each group was about 30 students which was average number of students in seminars) to ensure that all students understand the program content. Every session took about an hour and it was done after the time of the seminar, the sessions were distributed among researchers to cover the whole sample. Data show presentations, videos and posters were used to make the sessions interesting. The researchers used simple language with no scientific terms. Motivation and reinforcement techniques as praise, distributing a plastic bag contains booklets, pens and interesting photos were used to enhance active participation.

5- Evaluation phase: Evaluation of the effect of the health education intervention carried out through post-test after two months from intervention using the same data collection forms as in the pre-test by comparing result of pre and post test.

Statistical analysis: Data entry and statistical analysis were done using SPSS 19.0 statistical software package. Data were presented using descriptive statistics in the form of frequencies and percentages for qualitative variables, and means and standard deviations for quantitative variables. Comparison was done by McNemar Chi-Square test and paired $t$ tests. Statistical significance was considered at $\mathrm{p}$-value $<0.05$.

\section{Results}

As regarding socio-demographic characteristics of the studied sample, Table 1 demonstrated that $75 \%$ of studied students were $\geq 20$ years (maximum age was 23 years old), 60\% females, $57.2 \%$ from theoretical college ,56\% seniors, $69.1 \%$ had good degree $55 \%$ from urban area, $68 \%$ live with their family with good studentparents relationship (61.9\%), good friendship $(78.3 \%)$ and Religious commitment (74\%).

Figure 1 identified the prevalence of risky behaviors before and after program implementation. Dieting, nutritional and smoking behaviors took the least satisfactory scores respectively.

As regard the difference between pre and post test regarding satisfactory nutritional behavior among the studied sample as demonstrated in table 2: The dietary behavior of the students showed highly statistical significant improvements after the intervention as regard nutritional behavior. This was 
revealed in all areas of nutritional behavior especially regarding frequency of vegetables eating/day in which $76.7 \%$ of the students had satisfactory behaviors in post test compared with $5.7 \%$ in pre test $(\mathrm{p}<0.001)$. Also, total satisfactory nutritional behavior increase from $17.7 \%$ in pre test to61.8\% in post test with highly statistical significant difference $(\mathrm{p}<0.001)$.

Table 3 illustrated that difference between pre and post test regarding dieting behavior among the studied group. It revealed that total satisfactory dieting behavior among over weight \& obese students had significantly improved in post test to $66.2 \%$ compared to $10 \%$ in pretest with highly statistical significant difference $(\mathrm{p}<0.001)$.

Table 4 represented difference between pre and post test regarding smoking habits among the studied sample. It demonstrated that Total satisfactory smoking habits have improved from $33.3 \%$ in pretest to $68.2 \%$ in post test with highly statistical significant difference $(\mathrm{p}<0.001)$ (it included changing in opinion about smoking, trials to quit smoking and those who actually quitted smoking).

Table 5 represented difference between pre and post test regarding frequency of intake of tea, coffee and other substances among the studied group. It revealed that there was change behavior toward healthy one and improved from $85.3 \%$ in pretest compared to $90.6 \%$ in posttest with highly statistical significant difference $\quad(p<0.001)$ regarding these items.

As regard the pre and post test results for some safety behaviors among the studied group as demonstrated in table 6. There were no students carrying weapon, attempt to suicide or involved in sexual intercourse. Total satisfactory safety behaviors increase from $86.2 \%$ in pre test to $94.8 \%$ in post test with highly statistical significant difference $(\mathrm{p}<0.001)$.

Table 7 showed that there was improvement in total satisfactory driving behaviors among the students who drive a car from $58.4 \%$ in pretest to $72.3 \%$ in post test with statistically significant difference $(\mathrm{p}=0.016)$.

Table 8 illustrated correlation between total satisfactory scores of risky health behaviors and socio-demographic characteristics of the studied sample. It revealed that students $\geq 20$ years, females, seniors, having good degree, from urban area, living with their family, with good parents relationship, good friendship and with religious commitment had improvement in post test with highly statistical significant difference $(\mathrm{p}<0.05)$.

\section{Discussion}

When adolescents take one risk behavior, they also tend to take other risks. The interrelationship or cluster of health risk behaviors can be labeled as "risk behavior syndrome" that occurs in different combinations ${ }^{(16)}$. This study was carried out in order to identify the frequency of each type of health risk behaviors among college students, in addition to compare the difference in this frequency before and after an organized health education program.

The socio-demographic characteristics of studied sample were those of typical adolescent university students, with a higher percentage of the females, more than 20 years old, derived from theoretical faculties, seniors with last degree in the faculty as good. Most of them were from urban areas live with their families where good parents' relationship was common. In addition 
most of them enjoy good friendship and religious commitment (as believing in the religion's role in protecting against risky behaviors and following basic religion instructions as praying) as clarified in table 1.

The prevalence of unhealthy risk behaviors before and after intervention program was noted in figure 1 , where unhealthy dieting behavior took the lowest satisfactory score (10\%), followed by unhealthy nutritional behavior (17\%) and smoking behavior $(33.3 \%)$. Of course the unhealthy dieting behavior (high BMI and physical inactivity) are the results of unhealthy nutritional behavior. The bad nutritional behavior may be explained by large number of fast food places all around the university, with delicious taste of this type of food. An alternative explanation is due to most of the students spend more than half of the day outside their homes forcing them to use these types of food and may be lack of knowledge and healthy food culture about the criteria of health diet and how many calories and fat energy ratio they need.

In consistence with these results a comparative study by Rabab et al (17) between Egyptian and Saudi adolescent females, ranked unhealthy nutritional and dieting behaviors as the most common, with one in four students of both Egyptian and Saudi female adolescents reported that they are either slightly overweight or very obese. Another study done by Malakeh $\mathbf{2 0 1 5}^{(18)}$ who found smoking (55\%), physical inactivity (15\%) and unhealthy dieting (14\%) as the most frequent health risk behavior. In this instance, physical exercise played an important role in regulating the metabolic profile parameters as the significant decrease of most of these parameters is more among those who followed diet and exercise regimen.

As well as in a study done by Vanphanom et al $2011^{(19)}$ who reported that smoking and drinking alcohol are the most prevalent risky behaviors. This explains the imitation theory of peers. Smoking behavior as well as the continuation of smoking can be referred to the peer effect, the influence of family members and the availability of cigarettes with affordable prices. Current smokers were introduced to smoking by a friend and they smoked because their friends did so. University students face social, emotional and educational challenges when they enter the university and also Stress was the main reason for participants to start and/or continue smoking, followed by belonging and being cool.

Nutritional behavior among the studied sample was listed in table 2 , significant change occurred in the total nutritional behavior after the health education program. The marked change in the nutritional behavior was noticed in consumption of fast food, nippling and regular meals times that can be explained by availability of large number of fast food restaurants all around the university with affordable prices. In addition they spend a lot of time in the university with absence of the chance to follow regular meal times. The most noted improvement after intervention as regards the type of the used food was in the use of vegetables, because most of Egyptian from their childhood hate eating vegetables, in addition most of the mothers are working, depending upon delivery and fast food with absence of meals containing vegetables. In a study implemented by Eaton et al $2008{ }^{(20)}$ who found that, $21.4 \%$ of the study population reported meeting the recommended serving suggestion of 
five or more fruits and vegetables a day. Compared to study done by Monterio et al 2010 ${ }^{(21)}$ who noticed that less than half of the students meet the recommended daily servings of fruits and vegetables.

The dieting behavior was illustrated in table 3that indicated most of the sample was of normal BMI, after implementation of the program there was significant increase in the number of those who tried to make a diet and followed a physical activity program, these changes have a positive impact on their physical and psychological health. The prevalence of overweight in a study performed by Eaton et al $2008{ }^{(20)}$ was $15.6 \%$, obese was $11.4 \%$. They also noticed that over half $(56.8 \%)$ of the participants met the physical activity recommendations and only $2 \%$ of them did not get at least 60 minutes of physical activity on any day during the week. In another study done by Jill et al 2012(22) who found that over $35 \%$ of students spend three or more hours per day in sedentary behavior as watching $\mathrm{TV}$ and playing computer games. As well as Rey et al $\mathbf{2 0 0 8}{ }^{(23)}$ tied the relation between physical activity and body weight in the terms of Accumulating 60+ minutes of moderate/vigorous physical activity 5 or more days/week was both independently associated with weight status and remained significant after controlling for all covariates in the regression models, which suggests that meeting the physical activity recommendation is an important factor related to weight status.

Smoking habits were shown in table 4, no significant difference between pre and post intervention as regards prevalence of smoking (7.7and 6\% respectively). The effect of health education was obvious in change in number of smoked cigarettes per day with decrease in the number of students smoked more than five cigarettes per day. Also the change in number of smoking cessation trials was increased significantly after the program. Interestingly the number of those who perceive smoking harmful was increased significantly. The absence of change in prevalence in smoking may be explained by that it is a habit and behavior that needs longer period to stop it and the same person may enter the cycle of changing behavior many times with multiple relapses until exit from the circle occurs. This may be due to the failure, in most situations and trials, to provide the necessary multidisciplinary support. Also the change in behavior needs not only health education but more incorporated and integrated actions. The change in the previous three items may be due to the knowledge obtained from the program which they perceived it as vital. In consistence with these results of the study performed by Teuku et al 2013 (24) who suggested that their health education programs were effective in increasing students' knowledge about health-related aspects of cigarette smoking.

Similarly in a study performed by Islam and Johnson $2005{ }^{(25)}$ that showed that, after the implementation of the tobacco prevention education program, $89.1 \%$ of the students expressed that they became less desirable to smoke and $92.3 \%$ of them became more willingly to stop smoking. A previous metaanalysis of 47 school-based smoking programs showed that $98 \%$ of the reviewed programs successfully increased participants' knowledge ${ }^{(26)}$. In contrast with Flay 2009 (27) who concluded that only six of 12 reviews found positive effects of tobacco use prevention programs on smoking behaviors, with two reporting 
promising effects, and three no effects. These results were explained by Dobbins et al 2008 (28) who recommended that, in order to decrease the rate of adolescent smoking, the tobacco prevention education should be implemented and promoted before students' initiation of tobacco use to convey the knowledge of tobacco hazard and form the positive attitudes against smoking. Smoking was often seen as a habit not an addiction. If a person wanted to quit smoking, s/he could do it without any additional assistance.

The health risks and consequences of smoking were underestimated by the students, and they expressed no interest in quitting or taking familial advice against smoking seriously. Youth do not tend to value or follow the advice given to them by their parents and or teachers on smoking. This is largely because they perceive being told not to smoke by one who does so him/herself as meaningless hypocrisy.

Table 5clarified the difference between pre and post test regarding intake of tea, coffee and other substances among the studied sample. A noticed significant reduction in the use of these substances was noticed after program implementation except for coffee that can be referred to caffeine present in coffee with its dependence effect. Consistently college students consume some form of caffeine on a daily basis, making this substance the most commonly used drug in the world ${ }^{299}$. The results of a study done by Sifferlin $2013^{(30)}$ who found that 50 percent of college students drank at least one to four energy drinks per month, so coffee has become more popular than soda among adults. In a study done by Avena et al $2008{ }^{(31)}$, they reached to a result that caffeine use is associated with impulsivity, sensation seeking, and risk taking behaviors.

Violence related behavior and safety behaviors were assessed in table 6, marked improvement after the program was noticed especially in the item of following traffic rules and following safe behavior with using instruments at home. In Egypt most of Egyptians don't have any idea about traffics and its rules in addition to haphazard design of streets so not following traffic rules was not a surprise. In consistence with these results Bokhorst et al $2010{ }^{(32)}$ noted that risky traffic behavior is the commonest risk behavior among adolescents and they explained that by adolescents travel increasingly large distances as road users and they can make use of new modes of transport. Consistently Feenstra et al $2010{ }^{(33)}$ named risky traffic behavior as the main cause of mortality especially among youth. In the same line, Hans et al 2014 (34) recommended in his study to integrate courses about traffics in schools since childhood to make an established behavior. In addition Rahul et al $2008{ }^{(35)}$ found that the most common violence behavior was carrying a weapon.

The driving behavior among students who drive cars was assessed in table 7 , using seat belt (helmets), using mobile phones while driving and following the allowed speed were the most significantly changed items after program implementation. As there is no strict rules that are applied on those who not follow proper driving behaviors so most of adolescents not follow such rules. In addition most of them are not aware about why to wear seat belt or helmets, or why not to stop talking in cell phones while driving. Also most of roads in Egypt are not observed by radar devices so most of the drivers usually don't follow the allowed speed. In a 
study performed by Sharma et al $\mathbf{2 0 0 7}$

(36) they reported that More than half $(52.4 \%)$ of sample does 'not always wearing a seat belt and never wearing a helmet.

In table 8 the correlation between total score of risk behaviors and the sociodemographic criteria of the sample was studied. Significant relation between all socio-demographic criteria of the students in study sample and the risky behavior was reflected that may be referred to that most of risk behaviors are multi-factorial and the difference in social class, age, friendship and residence markedly enhance or arrest the risky behavior. As well as Roberto et al $2014{ }^{\text {(37) }}$ who found that only gender was associated with risk behavior with higher prevalence among males especially violent and drinking behavior. In a study performed by Mark and Elsie 2004 ${ }^{(38)}$ who found that the health of rural resident adolescents was worse than urban and contributed that to adoption of risk behavior specially smoking, physical inactivity and unhealthy diet in rural adolescents. In consistence Atav and Spencer 2002 (39) noted differences in risk behaviors regarding use of tobacco, alcohol, and illegal substances; sexual activity; and carrying weapons with higher rate in rural residence. In congruent with Springer et al $2006^{(40)}$ who found a strong relationship between family supports, parental relations and family ties with risk behavior especially physical fighting, victimization, suicidal ideation, substance use, and sexual intercourse). In a study performed by Gonzales et al $2008{ }^{(41)}$ they found that use praise and rewards to reinforce desirable behavior, replace criticism and physical punishment with mild and consistent negative consequences for undesirable behavior and increase positive involvement with their children can markedly decrease risk behavior. Analyses of results of a study done by James et al $2005{ }^{(42)}$ suggested that peer influence was small but reliable when both selection effects and parallel events were taken into account. Lynn et al $2013{ }^{(43)}$ reached to a result that adolescent's religious commitment significantly predicted all health-promoting behaviors (nutrition, physical activity, safety, health practices awareness, stress management).

College students are following multiple health risk behaviors that need more integrated efforts and continuous health education programs to change such behaviors as recommended by Zaki 2009 (44), Eid et al $2015^{(45)}$ and Abdelwahid et al $2012^{(46)}$. Finally, the information provided will allow other research groups to benefit from the collective experience of the study team and facilitate the implementation of well- designed programs to address the lack of quality interventions in this important public health issue.

\section{Conclusion}

Health risk behaviors are common among college students, and raising awareness by regular health education programs can dramatically change the profile of these behaviors.

\section{Limitations of the study}

- The study questionnaire was long that needed a longer time for completing it.

- Studying multiple risk factors was to some extent confusing so separate study for every risk factor may be more useful.

- Some topics in the questionnaire were rejected to be discussed specially the item of sexual behavior.

- Big sample size was a great 
burden on the researchers.

\section{Acknowledgment}

All thanks and appreciation for all students who shared in making this work complete and valuable.

\section{Funding}

All the research charges were funded by the authors.

\section{Conflicts of interest}

We have no conflict of interest to declare.

\section{References}

1) Qin L, Knol MJ, and Corpeleijn E.(2010): Does physical activity modify the risk of obesity for type 2 diabetes: a review of epidemiological data. Eur $\mathbf{J}$ Epidemiol; 25(1):5-12.

2) GrøntvedA., and Hu F.B. (2011): Television viewing and risk of type 2 diabetes, cardiovascular disease, and all-cause mortality: a metaanalysis. JAMA;305(23):2448-55.

3) Chiolero A., Wietlisbach V, Ruffieux C, Paccuad $F$ and Cornuz J. (2006): Clustering of risk behaviours with cigarette consumption: a population based survey, prev. Med. (42): 348-353.

4) Poortinga W. (2007): The prevalence and clustering of four major lifestyle risk factors in an English adult population. Prev, Med. 44: 124-128.

5) Danaei G, Ding EL, and Mozaffarian D. (2009): The preventable causes of death in the United States: comparative risk assessment of dietary, lifestyle, and metabolic risk factors. PLoS Med; 6(4):e1000058.

6) Lloyd D.M., Hong Y., Labarthe D, (2010): Defining and setting national goals for cardiovascular health promotion and disease reduction: the American Heart Association's strategic Impact Goal through 2020 and beyond. Circulation; 121(4):586-613.
7) Lee, C.B. (2013): Adolescent substance use. Funded by: Legacy Conrad N. Hilton Foundation Carnegie Corporation of New York Michael Alan Rosen Foundation.

8) Das P, and Horton R. (2012): Rethinking our approach to physical activity. The Lancet, 380(9838):18990.

9) Costanzo S, Di Castelnuovo A, and Donati MB. (2010): Alcohol consumption and mortality in patients with cardiovascular disease: a meta-analysis. J Am CollCardiol; 55(13):1339-47.

10) Finely, B. (2010): The role of the psychiatric nurse in a community substance abuse prevention program, Pub med. Montana State University, Missoula. Available at: http://www. ncbi. nlm. nih. gov/pubmed/2922349.

11) Wolfe, 1., \&Sleekman, J. (2012): School nurses: What it was and what it is. Pediatric Nursing, Chapter 28, pp. 403- 407.

12) Dean A.G., Dean J.a., Coulombeir D. and Brendel K.A. 1994: Epi-info version 6: a word processing data base and statistics program for epidemiology on microcomputers. Center for Disease Control.Atlanta, Georgia, USA.

\section{3) El-Gendy S., Elgendy} M.,Dawah A., ELdesouky R.,2013: Prevalence of Some Health Risk Behaviors among Benha University.Master thesis Benha University-Community Medicine Department.

14) Abd EL-Rahim I (2005): Health Risk Behaviors among Students of Private Universities In Egypt. MSc thesis, faculty of medicine, Ain shams university library.

15) World Health Organization (WHO). (2012): Body mass index (BMI) as measurement issue. and 
guidelines to classification. Genera, Switzerland.

16) Liu A, Kilmarx P, Jenkins RA. (2006): Sexual initiation, substance use, and sexual behavior and knowledge among vocational students in Northern Thailand.Inter Family

PlannPerspec, 2:126-135.

17) Rabab E, Samar E, Abdel H (2013).Health-Related Behaviors of Female Adolescent Students: A Comparative Study between Egypt and Saudi Arabia. Life Science Journal; 10(4).

18) Malakeh ZM (2015): Patterns of Health-Risk Behaviors among Jordanian Adolescent Students. Health: (7) No.1.

19) Vanphanom S, Sarah T, Elisabeth F(2011). Concurrent multiple health risk behaviors among adolescents in Luangnamtha province, Lao PDR. BMC Public Health, 11:36.

20) Eaton DK, Kann S, Kinchen S, Shanklin J, Ross J, Hawkins WA, Harris R, Lowry T, McManus D. Chyen C (2008): Youth risk behavior surveillance-United States. MMWR.SurveillSumm, 57(4): p. 1131.

21) Monterio AC, Jeremic $M$, Budden MC (2010). Can we have fries with that, please? Nutrion and physical activities among college students. Contemporary Issues in Education research. 3(11):1.

22) Jill MM, Eugene C F, Carol AC, Naima MM, David R B, Marsha LS, Betty PG(2012). Physical Activity, Screen Time, and Prevalence of Overweight/Obesity among Adolescents in a Creative, Problem-Solving Program. FNS ; 3(4).

23) Rey L, Vicente R, Moreno LA (2008). Sedentary behavior and obesity development in children and adolescents. NutrMetabCardiovasc Dis, 18(3): p. 242-51.

24) Teuku T, Richard J W, John C,and Paul RW (2013). The impact of education programs on smoking prevention: a randomized controlled trial among 11 to 14 year olds in Aceh, Indonesia. BMC Public Health, 13:367.

25) Islam $\mathbf{S} \mathbf{M}$, Johnson $\mathbf{C A}$ (2005). Influence of known psychosocial smoking risk factors on Egyptian adolescents' smoking behaviour. Health Promotion International, 20, 135-145.

26) Harris HM, Holtzman GW, Earley JA, Van Dillen LR (2010):Development and preliminary reliability testing of an assessment of patient independence in performing a treatment program: standardized scenarios.J Rehabil Med, 42(3):221-227.

27) Flay BR (2009): School-based smoking prevention programs with the promise of long-term effects. TobInduc Dis, 5(1):1-18.

28) Dobbins M, DeCorby $\mathbf{K}$, Manske S, Goldblatt E (2008): Review: effective practices for school-based tobacco use prevention. Prev Med, 46:289-297.

29) NicoleL O (2013). Caffeine Consumption Habits and Perceptions among University of New Hampshire Students. Thesis study. University of New Hampshire

30) Sifferlin A. (2013). What's in your energy drink?. Time, Retrieved from

http://healthland.time.com/2013/02/ 04/whats-in-your-energy-drink/

31) Avena NM, Rada $P$, Hoebel BG. (2008). Evidence for sugar addiction: Behavioral and neurochemical effects of intermittent, excessive sugar intake. NeurosciBiobehav Rev; 32:20-39. 
32) Bokhorst CL, Sumter SR, Westenberg PM (2010). Social support from parents, friends, classmates, and teachers in children and adolescents aged 9 to 18 years: Who is perceived as most supportive? In: Social Development, 19: 417-426.

33) Feenstra H, Ruiter R, Kok G (2010). Social-cognitive correlates of risky adolescent cycling behavior. In: BMC Public Health, 10 (1): 408.

34) Hans F, Robert AC, Gerjo K (2014). Evaluating traffic informers: Testing the behavioral and socialcognitive effects of an adolescent bicycle safety education program. Accident Analysis \& Prevention; 73: 288-295.

35) Rahul S, Vijay LG, Sanjay C (2008). Risk Behaviors Related to Inter-personal Violence among School and College-going Adolescents in South Delhi. Indian Journal of Community Medicine, 33 (2).

36) Sharma R, Grover VL, Chaturvedi S. (2007). Health-risk behaviors related to road safety among adolescent students. Indian J Med Sci; 61: 656-62.

37) Roberto J, Nara M, Antônio C (2014): Factors Associated with Violent Behavior among Adolescents in Northeastern Brazil. The Scientific World Journal Volume (2014), Article ID 863918, 7 pages.

38) Mark SE, Elsie RP (2004). The Importance of Place of Residence: Examining Health in Rural and Nonrural Areas Am J Public Health; 94(10): 1682-1686.

39) Atav S, Spencer GA. (2002): Health risk behaviors among adolescents attending rural, suburban, and urban schools: a comparative study. FamCommunity Health. 25(2):53-64.

40) Springer A, Parcel $\underline{\text { G, Baumler E, Ross M (2006). }}$ Supportive social relationships and adolescent health risk behavior among secondary school students in El Salvador.

SocSciMed. ;62(7):1628-40.

41) Gonzales NA, Dumka LE, Millsap RE, Bonds D, Gottschall A, Wheeler L, German $M$, Mauricio A, Dillman C(2008). Effects of the Bridges to High School Program. Paper presented at the Society for Prevention Research 16th Annual Meeting, San Francisco, CA.

42) James J, Hart B, Tonya D (2005). Peer Influences on Risk Behavior: An Analysis of the Effects of a close friend. Developmental Psychology Copyright by the American Psychological Association; 41 (1): 135-147.

43) Lynn R, Kristopher LA, Sanna T, Karen J (2013). Predictors of Adolescents' Healthpromoting Behaviors Guided by Primary Socialization Theory. J Spec PediatrNurs. 2013 October; 18(4): 277-288.

44) Zaki H. (2009): Assessment of youth risk behaviors in Zagazig University. Master theses faculty of nursing Zagazig University p. 89-91.

45) Eid KH., Selim S, Ahmed D, El-sayed A (2015):Smoking problem among Helwan Universitystudents: Practical versus theoretical faculty. Egyptian Journal of Chest Diseases and Tuberculosis.p 385.

46) Abdelwahid A.E., Ali H., Diab M.A. (2012): Patterns of smoking among undergraduates of Suez Canal University, Egypt, Open Access Sci. Rep. 5771 (12) (2012). 
Table (1): Socio-demographic characteristics of the studied sample $($ No. $=853)$ *Juniors: $1^{\text {st }}$ three year. $* *$ Student hostel, with friends, private flats.

\begin{tabular}{|c|c|c|c|}
\hline \multicolumn{2}{|c|}{ Socio demographic characteristics } & \multirow{2}{*}{$\begin{array}{l}\text { No. } \\
213\end{array}$} & \multirow{2}{*}{$\begin{array}{c}\% \\
25.0\end{array}$} \\
\hline & $<20$ years & & \\
\hline Age (20.8 \pm 1.7$)$ & $\geq 20$ years & 640 & 75.0 \\
\hline \multirow{2}{*}{ Gender } & Male & 341 & 40.0 \\
\hline & Female & 512 & 60.0 \\
\hline \multirow{2}{*}{ Collage } & Theoretical & 488 & 57.2 \\
\hline & Practical & 365 & 42.8 \\
\hline \multirow{2}{*}{ Grade } & Juniors* & 375 & 44.0 \\
\hline & Seniors & 478 & 56.0 \\
\hline \multirow{2}{*}{ Degree } & Bad & 264 & 30.9 \\
\hline & Good & 589 & 69.1 \\
\hline \multirow{2}{*}{ residence } & Rural & 384 & 45.0 \\
\hline & Urban & 469 & 55.0 \\
\hline \multirow[b]{2}{*}{ Place of living } & With family & 580 & 68.0 \\
\hline & $\begin{array}{r}\text { Away from } \\
\text { family** }\end{array}$ & 273 & 32.0 \\
\hline \multirow{2}{*}{$\begin{array}{c}\text { Student- } \\
\text { parent } \\
\text { relationship }\end{array}$} & Good & 528 & 61.9 \\
\hline & Bad & 325 & 38.1 \\
\hline \multirow{2}{*}{ Friendship } & Good & 668 & 78.3 \\
\hline & Bad & 185 & 21.7 \\
\hline \multirow{2}{*}{$\begin{array}{l}\text { Religious } \\
\text { commitment }\end{array}$} & Yes & 631 & 74.0 \\
\hline & No & 222 & 26.0 \\
\hline
\end{tabular}


Table (2): Difference between pre and post test regarding satisfactory nutritional behavior among the studied sample.

\begin{tabular}{|c|c|c|c|c|c|}
\hline \multirow{2}{*}{$\begin{array}{l}\text { Satisfactory Nutritional } \\
\text { behaviour regarding }\end{array}$} & \multicolumn{2}{|c|}{ Pre } & \multicolumn{2}{|c|}{ Post } & \multirow{2}{*}{ p. value } \\
\hline & No. & $\%$ & No. & $\%$ & \\
\hline Regular meals & 214 & 25.1 & 501 & $\begin{array}{r}58 . \\
7\end{array}$ & $<0.001$ \\
\hline Nippling (snacks) & 187 & 21.9 & 525 & $\begin{array}{r}61 . \\
5\end{array}$ & $<0.001$ \\
\hline Fast food & 272 & 31.9 & 611 & $\begin{array}{r}71 . \\
6\end{array}$ & $<0.001$ \\
\hline Type of Used fat & 86 & 10.1 & 217 & 25. & $<0.001$ \\
\hline $\begin{array}{r}\text { 1-Frequency of fruits } \\
\text { eating/day } * 1\end{array}$ & 81 & 9.5 & 628 & $\begin{array}{r}73 . \\
6\end{array}$ & $<0.001$ \\
\hline $\begin{array}{r}\text { 2-Frequency of } \\
\text { vegetables } \\
\text { eating/day*1 }\end{array}$ & 49 & 5.7 & 654 & $\begin{array}{r}76 . \\
7\end{array}$ & $<0.001$ \\
\hline $\begin{array}{r}\text { 3-Frequency of drinking } \\
\text { milk/day*2 }\end{array}$ & 171 & 20.0 & 498 & $\begin{array}{r}58 . \\
4\end{array}$ & $<0.001$ \\
\hline $\begin{array}{c}\text { Total satisfactory } \\
\text { nutritional behavior }\end{array}$ & 151 & 17.7 & 527 & $\begin{array}{r}61 . \\
8\end{array}$ & $<0.001$ \\
\hline Total & 853 & 100.0 & 853 & $\begin{array}{r}100 \\
.0\end{array}$ & \\
\hline
\end{tabular}

paired $t$ test was used 
Table (3): Difference between pre and post test regarding BMI, dieting behavior and physical activity among the studied sample.

\begin{tabular}{|c|c|c|c|c|c|c|}
\hline \multirow{2}{*}{\multicolumn{2}{|c|}{ Characteristics }} & \multicolumn{2}{|c|}{ Pre } & \multicolumn{2}{|c|}{ Post } & \multirow{2}{*}{$\begin{array}{l}\text { p. } \\
\text { value }\end{array}$} \\
\hline & & No. & $\%$ & No. & $\%$ & \\
\hline \multirow{3}{*}{$\begin{array}{r}\text { BMI } \\
26.3 \pm 4.2\end{array}$} & Normal & 462 & 54.2 & 509 & 59.7 & \multirow{3}{*}{$<0.001$} \\
\hline & Overweight & 320 & 37.5 & 311 & 36.5 & \\
\hline & Obese & 71 & 8.3 & 33 & 3.9 & \\
\hline Total & & 853 & 100.0 & 853 & 100.0 & \\
\hline \multirow{2}{*}{ Dieting $(n=391)$} & Yes & 123 & 33.8 & 208 & 53.2 & \multirow{2}{*}{$<0.001$} \\
\hline & No & 268 & 66.2 & 183 & 46.8 & \\
\hline \multirow{2}{*}{$\begin{array}{c}\text { Physical } \\
\operatorname{activity}(\mathrm{n}=391) *\end{array}$} & Yes & 39 & 10.0 & 311 & 79.5 & \multirow{2}{*}{$<0.001$} \\
\hline & No & 351 & 90.0 & 80 & 20.5 & \\
\hline \multicolumn{2}{|c|}{$\begin{array}{r}\text { Total satisfactory dieting } \\
\text { behavior } *\end{array}$} & 39 & 10.0 & 259 & 66.2 & $<0.001$ \\
\hline & Total & 391 & 100.0 & 391 & 100.0 & \\
\hline
\end{tabular}

*Over weight \& obese students.

McNemar Chi-Square was used 
Table (4): Difference between pre and post test regarding smoking behavior among the studied sample.

\begin{tabular}{|c|c|c|c|c|c|c|}
\hline \multirow{2}{*}{ Smoking behaviors } & & \multicolumn{2}{|l|}{ Pre } & \multicolumn{2}{|c|}{ Post } & \multirow{2}{*}{$\begin{array}{c}\text { p. } \\
\text { value }\end{array}$} \\
\hline & & No. & $\%$ & No. & $\%$ & \\
\hline \multirow{2}{*}{ Smoking status } & Yes & 66 & 7.7 & 51 & 6.0 & \multirow[t]{2}{*}{0.151} \\
\hline & No & 787 & 92.3 & 802 & 94.0 & \\
\hline Total & & 853 & 100.0 & 853 & 100.0 & \\
\hline \multirow{2}{*}{ No./day $(n=66)$} & $<5$ & 26 & 39.4 & 50 & 75.8 & \multirow[t]{2}{*}{$<0.001$} \\
\hline & $\geq 5$ & 40 & 60.6 & 16 & 24.2 & \\
\hline \multirow{2}{*}{$\begin{array}{l}\text { Site of smoking } \\
(n=66)\end{array}$} & Indoor & 35 & 53.0 & 21 & 31.8 & \multirow[t]{2}{*}{0.014} \\
\hline & Outdoor & 31 & 47.0 & 45 & 68.2 & \\
\hline \multirow{2}{*}{$\begin{array}{l}\text { Smoking Cessation } \\
\text { rial }(\mathrm{n}=66)\end{array}$} & Yes & 13 & 20.0 & 28 & 42.4 & \multirow[t]{2}{*}{0.005} \\
\hline & No & 53 & 80.0 & 38 & 57.6 & \\
\hline \multirow{2}{*}{$\begin{array}{l}\text { Opinion about } \\
\text { smoking }(n=66)\end{array}$} & Harmful & 20 & 30.0 & 58 & 87.9 & \multirow[t]{2}{*}{$<0.001$} \\
\hline & $\begin{array}{c}\text { Not } \\
\text { harmful }\end{array}$ & 46 & 70.0 & 8 & 12.1 & \\
\hline \multicolumn{2}{|c|}{\begin{tabular}{|l} 
Total satisfactory smoking \\
behavior $(n=66)$
\end{tabular}} & 22 & 33.3 & 45 & 68.2 & $<0.001$ \\
\hline \multicolumn{2}{|l|}{ Total } & 66 & 100.0 & 66 & 100.0 & \\
\hline
\end{tabular}

McNemar Chi-Square was used 
Table (5): Difference between pre and post test regarding intake of tea, coffee and other substances among the studied sample.

\begin{tabular}{|c|c|c|c|c|c|c|}
\hline \multirow{2}{*}{ Items } & \multirow{2}{*}{ variable } & \multicolumn{2}{|c|}{ Pre } & \multicolumn{2}{|c|}{ Post } & \multirow{2}{*}{$\begin{array}{l}\text { p. } \\
\text { value }\end{array}$} \\
\hline & & No. & $\%$ & No. & $\%$ & \\
\hline \multirow{2}{*}{$\begin{array}{l}\text { Frequency } \\
\text { of tea intake/ } \\
\text { day }\end{array}$} & $<3$ & 547 & 64.1 & 635 & 74.4 & \multirow[t]{2}{*}{$<<0.001$} \\
\hline & $\geq 3$ & 306 & 35.9 & 218 & 25.6 & \\
\hline \multirow{2}{*}{$\begin{array}{l}\text { Frequency } \\
\text { of Coffee } \\
\text { intake/ day }\end{array}$} & $<3$ & 831 & 97.4 & 841 & 98.6 & \multirow[t]{2}{*}{0.083} \\
\hline & $\geq 3$ & 22 & 2.6 & 12 & 1.4 & \\
\hline \multirow{2}{*}{$\begin{array}{r}\text { Substance } \\
\text { abuse }\end{array}$} & Yes & 45 & 5.3 & 11 & 1.3 & \multirow[t]{2}{*}{$<0.001$} \\
\hline & No & 808 & 94.7 & 842 & 98.7 & \\
\hline \multicolumn{2}{|c|}{$\begin{array}{c}\text { Total satisfactory } \\
\text { behaviors }\end{array}$} & 728 & 85.3 & 773 & 90.6 & $<0.001$ \\
\hline \multicolumn{2}{|c|}{ Total } & 853 & 100.0 & 853 & 100.0 & \\
\hline
\end{tabular}

Paired $t$ and McNemar Chi-Square tests were used 
Table (6): Difference between pre and post test regarding some safety behaviors among the studied sample.

----- = invalid

\begin{tabular}{|c|c|c|c|c|c|c|}
\hline \multirow{2}{*}{ Variable } & & \multicolumn{2}{|c|}{ Pre } & \multicolumn{2}{|c|}{ Post } & \multirow{2}{*}{ P.value } \\
\hline & & No. & $\%$ & No. & $\%$ & \\
\hline \multirow{2}{*}{$\begin{array}{l}\text { Follow } \\
\text { traffic Rules }\end{array}$} & Yes & 469 & $\overline{55.0}$ & 752 & 88.2 & \multirow[b]{2}{*}{$<0.001$} \\
\hline & No & 384 & 45.0 & 101 & 11.8 & \\
\hline \multirow{2}{*}{$\begin{array}{l}\text { Follow Safe } \\
\text { behavior with using } \\
\text { instruments at home } \\
\text { (as knives and } \\
\text { electrical devices) }\end{array}$} & Yes & 613 & 71.9 & 743 & 87.1 & \multirow{2}{*}{$<0.001$} \\
\hline & No & 240 & 28.1 & 110 & 12.9 & \\
\hline \multirow{2}{*}{ carry a weapon } & Yes & 0 & 0.0 & 0 & 0.0 & \multirow[t]{2}{*}{----- } \\
\hline & No & 853 & 100.0 & 853 & 100.0 & \\
\hline \multirow{2}{*}{$\begin{array}{l}\text { Engaged in } \\
\text { Physical fight in } 1^{\text {st }} \\
\text { term }\end{array}$} & Yes & 85 & 10.0 & 54 & 6.3 & \multirow{2}{*}{0.006} \\
\hline & No & 768 & 90.0 & 799 & 93.7 & \\
\hline \multirow{2}{*}{ Attempt suicide } & Yes & 0 & 0.0 & 0 & 0.0 & \multirow[t]{2}{*}{----- } \\
\hline & No & 853 & 100.0 & 853 & 100.0 & \\
\hline \multirow{2}{*}{$\begin{array}{l}\text { Involved in sexual } \\
\text { intercourse }\end{array}$} & Yes & 0 & 0.0 & 0 & 0.0 & \multirow[t]{2}{*}{----- } \\
\hline & No & 853 & 100.0 & 853 & 100.0 & \\
\hline \multicolumn{2}{|c|}{$\begin{array}{l}\text { Total satisfactory safety } \\
\text { behaviors }\end{array}$} & 735 & 86.2 & 809 & 94.8 & $<0.001$ \\
\hline & Total & 853 & 100.0 & 853 & 100.0 & \\
\hline
\end{tabular}

McNemar Chi-Square was used 
Table (7): Difference between pre and post test regarding driving behavior among the studied students who drive a car $(n=137)$.

\begin{tabular}{|c|c|c|c|c|c|c|}
\hline \multirow{2}{*}{ variable } & & \multicolumn{2}{|c|}{ Pre } & \multicolumn{2}{|c|}{ Post } & \multirow{2}{*}{ P.value } \\
\hline & & No. & $\%$ & No. & $\%$ & \\
\hline \multirow{2}{*}{ Having license } & Yes & 83 & 60.6 & 86 & 62.8 & \multirow{2}{*}{0.709} \\
\hline & No & 54 & 39.4 & 51 & 37.2 & \\
\hline \multirow{2}{*}{$\begin{array}{l}\text { Using Seat belt/ } \\
\text { helmet }\end{array}$} & Yes & 76 & 55.5 & 109 & 79.6 & \multirow{2}{*}{0.002} \\
\hline & No & 61 & 44.5 & 28 & 20.4 & \\
\hline \multirow{2}{*}{$\begin{array}{l}\text { Using mobile while } \\
\text { driving }\end{array}$} & Yes & 27 & 19.7 & 8 & 5.8 & \multirow{2}{*}{$<0.001$} \\
\hline & No & 110 & 80.3 & 129 & 94.2 & \\
\hline \multirow{2}{*}{$\begin{array}{l}\text { Follow the allowed } \\
\text { Speed }\end{array}$} & Yes & 52 & 38.0 & 71 & 51.8 & \multirow{2}{*}{0.021} \\
\hline & No & 85 & 62.0 & 66 & 48.2 & \\
\hline \multicolumn{2}{|c|}{$\begin{array}{c}\text { Total satisfactory driving } \\
\text { behaviors }\end{array}$} & 80 & 58.4 & 99 & 72.3 & 0.016 \\
\hline & Total & 137 & 100.0 & 137 & 100.0 & \\
\hline
\end{tabular}

McNemar Chi-Square was used

Table (8): Association between total satisfactory scores of risky health behaviors and sociodemographic characteristics pre/post scores.

\begin{tabular}{|c|c|c|c|c|c|c|}
\hline \multirow{3}{*}{\multicolumn{2}{|c|}{ Socio-demographic characteristics }} & \multicolumn{4}{|c|}{ Total satisfactory scores $(\geq 60 \%)$} & \multirow{3}{*}{ p. value } \\
\hline & & \multicolumn{2}{|c|}{ Pre } & \multicolumn{2}{|c|}{ Post } & \\
\hline & & No. & $\%$ & No. & $\%$ & \\
\hline \multirow{2}{*}{ Age } & $<20$ years & 109 & 28.1 & 239 & 37.9 & \multirow{2}{*}{0.001} \\
\hline & $\geq 20$ years & 279 & 71.9 & 392 & 62.1 & \\
\hline \multirow[t]{2}{*}{ Gender } & Male & 108 & 27.8 & 227 & 36.0 & \multirow{2}{*}{0.007} \\
\hline & Female & 280 & 72.2 & 404 & 64.0 & \\
\hline \multirow{2}{*}{ Grade } & Juniors & 114 & 29.4 & 246 & 39.0 & \multirow{2}{*}{0.002} \\
\hline & Seniors & 274 & 70.6 & 385 & 61.0 & \\
\hline \multirow{2}{*}{ Degree } & Bad & 102 & 26.3 & 242 & 38.6 & \multirow{2}{*}{$<0.001$} \\
\hline & Good & 286 & 73.7 & 389 & 61.6 & \\
\hline \multirow{2}{*}{ Residence } & Rural & 148 & 38.1 & 354 & 22.5 & \multirow{2}{*}{$<0.001$} \\
\hline & Urban & 240 & 61.9 & 277 & 77.5 & \\
\hline \multirow[b]{2}{*}{ Place of living } & With family & 201 & 51.8 & 427 & 67.7 & \multirow[b]{2}{*}{$<0.001$} \\
\hline & $\begin{array}{c}\text { Away from } \\
\text { family }\end{array}$ & 187 & 48.2 & 204 & 32.3 & \\
\hline \multirow{2}{*}{$\begin{array}{c}\text { Student- parent } \\
\text { relationship }\end{array}$} & Good & 226 & 58.2 & 471 & 74.6 & \multirow{2}{*}{$<0.001$} \\
\hline & Bad & 162 & 41.8 & 160 & 25.4 & \\
\hline \multirow{2}{*}{ Friendship } & Good & 238 & 61.3 & 463 & 73.4 & \multirow{2}{*}{$<0.001$} \\
\hline & Bad & 150 & 38.7 & 168 & 26.6 & \\
\hline \multirow{2}{*}{$\begin{array}{l}\text { Religious } \\
\text { commitment }\end{array}$} & Yes & 241 & 62.1 & 452 & 71.6 & \multirow{2}{*}{0.002} \\
\hline & No & 147 & 37.9 & 179 & 28.4 & \\
\hline Total & & 388 & $\begin{array}{r}100 . \\
0\end{array}$ & 631 & $\begin{array}{r}100 . \\
0\end{array}$ & \\
\hline
\end{tabular}

Paired $t$ test was used 


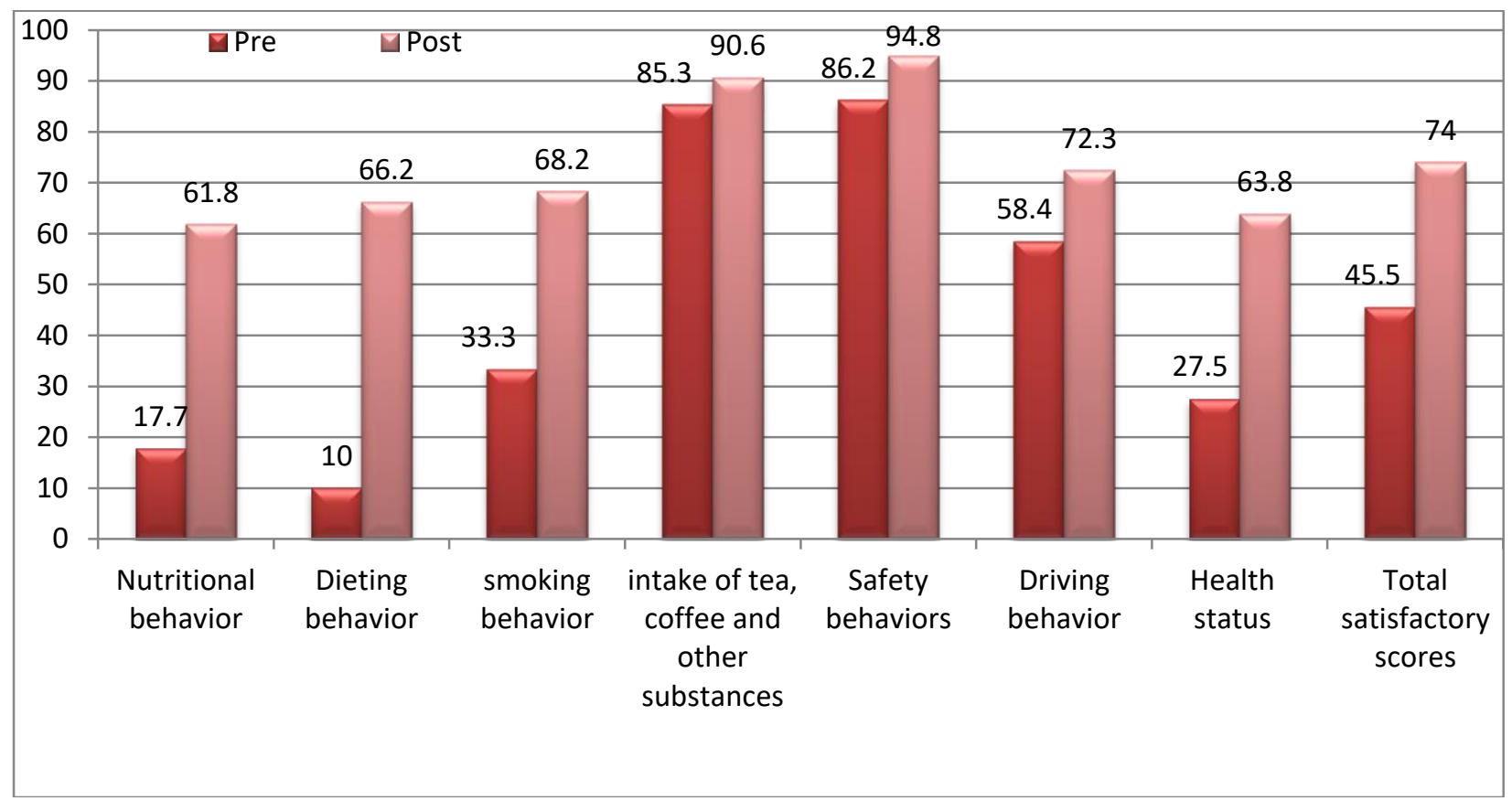

Figure (1): Difference between pre and post test regarding total satisfactory scores of risky health behaviors. 